\title{
Crystallographic Orientation-Spray Formed Hypereutectic Aluminium-Silicon Alloys
}

\author{
Hamilta de Oliveira Santos*, Marilene Morelli Serna, Nelson Batista de Lima, \\ Isolda Costa, Jesualdo Luiz, Rossi \\ Instituto de Pesquisas Energéticas e Nucleares, IPEN/CNEN-SP \\ Av. Lineu Prestes, 2242, 05508-000 Cidade Universitária, São Paulo, Brazil
}

Received: November 23, 2003; Revised: March 19, 2005

\begin{abstract}
Aluminium-silicon alloys have been wide accepted in the automotive, electric and aerospace industries. Preferred orientation is a very common condition for metals and alloys. Particularly, aluminium induces texture during the forming process. The preparation of an aggregate with completely random crystal orientation is a difficult task. The present work was undertaken to analyse the texture by X-ray diffraction techniques, of three spray formed hypereutectic Al-Si alloys. Samples were taken from a billet of an experimental alloy (alloy 1) and were subsequently hot-rolled and cold-rolled (height reduction), $72 \%$ and $70 \%$, respectively. The other used samples, alloys 2 and 3, were taken from cylinders liners. The results from the Laue camera showed texture just in the axial direction of alloy 3 . The pole figures also indicated the presence of a typical low intensity deformation texture, especially for alloy 3 . The spray formed microstructure, which is very fine, hinders the Al-Si texture formation during mechanical work.
\end{abstract}

\section{Introduction}

Keywords: spray forming, cylinder liners, Al-Si hypereutectic alloys

Some Al-Si alloys have characteristics such as good wear resistance, low coefficient of thermal expansion, combined with a high strength to mass ratio. Due to such properties, these alloys have been used in several applications from the automotive to aerospace and power industries ${ }^{1-4}$. The outstanding wear resistance is due to the high volumetric fraction of the silicon phase and intermetallics. Applications of the Al-Si alloys in the automotive industry, include engine blocks and parts of engines, particularly, cylinder liners. The main advantages for the use of these alloys are weight reduction, low fuel consumption and less emission of pollutants ${ }^{1,2}$.

The use of engine blocks made of hypereutectic aluminium alloys has been considered by many world manufacturers. Blocks of the $\mathrm{A} 117 \mathrm{Si} 4 \mathrm{CuMg}$ alloy are very difficult to cast. They have been produced by expensive processes, such as chill mould casting at low pressure. This process was necessary to attain refined silicon particles, used in the contact area between the cylinder liner and the piston rings. The conventional die cast $\mathrm{A} 19 \mathrm{Si} 3 \mathrm{Cu}$ alloy has been preferred due to economic reasons. However, the tribological properties of the late alloy do not favour its use in the combustion chamber area. The accepted solution is to use cylinder liners made of cast irons; cast or spray formed high silicon aluminium alloys, composites or coatings in this area ${ }^{2}$.

Hypereutectic alloys can be produced by ingot metallurgy ${ }^{1,2}$ or by rapid solidification processes, such as melt spinning ${ }^{4}$, atomisation ${ }^{4,5}$ and spray forming ${ }^{4-9}$. The use of casting for the production of these alloys is limited by the range of possible chemical compositions. That can be attributed to the formation of eutectics and coarse primary silicon phase, due to the low cooling rates associated to the ingot metallurgy. The distribution of coarse silicon particles in the alloy leads to low ductility and limited workability of the hypereutectic Al-Si alloys. Many of the problems associated with ingot metallurgy can be overcome by the spray forming techniques. The main advantage of the use of the spray forming process is the significant modification of size, morphology and distribution of the primary silicon phase in the matrix, comparatively to the conventional process. The refinement of the primary silicon particles is either achieved by spray forming hypereutectic Al-Si alloys or co-depositing fine Si particles.
The technology for producing cylinder liners by casting iron and spray forming aluminium alloys is well established. The use of aluminium alloys for such application was made possible by the admixture of large amounts of alloying elements that precipitate as hard particles. The use of such alloys is viable if these particles are finely dispersed, allowing further mechanical working.

Any aggregate characterised by a condition in which the distribution of crystal orientations is non-random is said to have a preferred orientation, or texture. Preferred orientation is a very common condition. For metals and alloys, it is most evident in wrought products. It is due to the tendency of the grains in a polycrystalline aggregate to rotate during plastic deformation. Each grain undergoes slip and rotation in a complex way that is determined by the imposed forces and by the slip and rotation of adjoining grains. In fact, preferred orientation is generally the rule, not the exception, and the preparation of an aggregate with completely random crystal orientation is a difficult task ${ }^{10}$.

The pure aluminium is highly strainable and it induces a particularised texture, common to the material and to the used forming process. However, it was noticed in previous work that larger amounts of silicon added to the aluminium produce a natural barrier that it prevents the texture formation ${ }^{11}$. In order to know the maximum limit of silicon addition that hinders the texture formation in the aluminium matrix is necessary to optimise materials, decreasing or intensifying a certain property already existent. In this work it was undertaken a crystallographic orientation study of spray formed hypereutectic Al-Si alloys. The texture was evaluated by X-ray diffraction and was performed in two spray formed hypereutectic Al-Si alloys taken from commercial cylinder liners and from an experimental alloy.

\section{Experimental}

The materials used in this work were produced by spray forming (Osprey Process), an experimental alloy and two alloys already in commercial use to produce cylinder liners. These materials are here denominated as alloy 1 (experimental alloy) and alloys 2 and 3 (commercial alloys). Alloy 1 was hot and cold rolled to simulate 
mechanical work in order to allow the analysis of its behavior regarding texture formation. The hot rolling was performed at $450{ }^{\circ} \mathrm{C}$ in $3 \%$ reduction step until to $72 \%$ total reduction in height or thickness. The cold rolling was accomplished in 5\% reductions step until a total reduction of $70 \%$ was attained.

The alloys 2 and 3 probably undergone mechanical working such as hot extrusion followed by swaging, typically used during the forming of billets into tubes used as cylinder liners. However, there is no information available of how and under which conditions these mechanical works were performed. The samples were removed from cylinder liners supplied by two different manufacturers, without any further mechanical work.

Table 1 displays the chemical composition of the three spray formed hypereutectic Al-Si alloys. The chemical compositions were obtained by atomic absorption spectrophotometry and the $\mathrm{Si}$ gravimetry.

After a suitable metalographic polishing, the specimens taken from the three materials were etched in a solution of $60 \mathrm{~mL}$ of deionised water, $10 \mathrm{~g}$ of $\mathrm{NaOH}$ and $5 \mathrm{~g}$ of $\mathrm{K}_{3} \mathrm{Fe}(\mathrm{CN})_{6}$. The specimens were analysed by optical microscopy (MO) and scanning electron microscopy (SEM).

The X-ray diffraction analyses were accomplished in two diffractometers; one of them fitted with a back-reflection Laue camera. It was used a $\mathrm{Cu}$ tube and $\mathrm{K} \alpha$ radiation. The exposure time in the Laue camera was 3 hours, 7 hours and 5 hours, for alloy 1, 2 and 3 , respectively. The working distance between the film and the specimen was $50 \mathrm{~mm}$, for a power of $40 \mathrm{~kW} / 30 \mathrm{~mA}$. The other used diffractometer was fitted with a scintillation detector, Mo radiation was used at a power of $40 \mathrm{~kW} / 20 \mathrm{~mA}$. The pole figures were accomplished by the Schulz reflection method and step scanning of $5^{\circ}$ for $\alpha$ and $\beta$ angles. The specimens taken from the cylinder liners were analysed in the radial direction, tangential and axial as shown in Figure 1. This figure presents a schematic drawing of a cylinder liner and the directions parallel to the incident X-ray beam irradiated into the Laue camera.

\section{Results and Discussion}

It is observed from the chemical composition of the three spray formed $\mathrm{Al}-\mathrm{Si}$ alloys, that a variation in quantity of $\mathrm{Si}, \mathrm{Ni}$ and $\mathrm{Cu}$ is present, see Table 1. Alloy 1 has very little $\mathrm{Mg}$ content in relation to the other ones and further, it has the highest amount of $\mathrm{Si}$ and $\mathrm{Cu}$ which accounts most for the formation of very fine primary silicon particles and intermetallics.

The optical micrographs of the three analysed Al-Si alloys show a homogeneous distribution of the primary silicon particles (Figure 2). These alloys contain a silicon concentration high above the eutectic composition (roughly $12.5 \%$ in mass), however, presenting a micro-

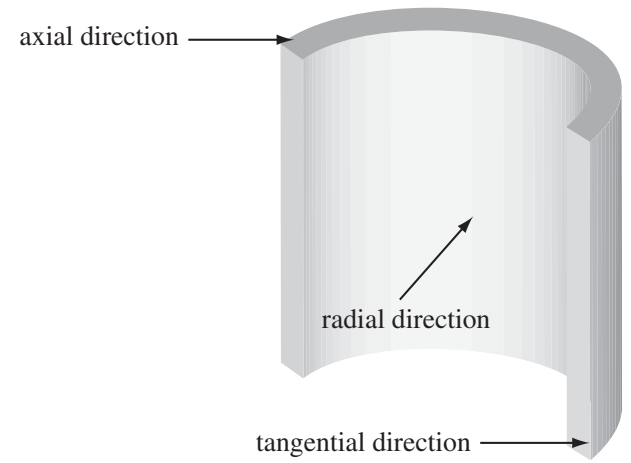

Figure 1. Schematics of a cylinder liner a section, where the used directions for the Laue photograph are shown.
Table 1. Chemical composition of spray formed hypereutectic Al-Si alloys (mass \%). The techniques used were atomic absorption spectrophotometry and $\mathrm{Si}$ gravimetry.

\begin{tabular}{lcclccc}
\hline Material & $\mathrm{Si}$ & $\mathrm{Mg}$ & $\mathrm{Ni}$ & $\mathrm{Cu}$ & $\mathrm{Fe}$ & $\mathrm{Al}$ \\
\hline Alloy 1 & 26.64 & 0.02 & 0.006 & 5.20 & 0.19 & bal. \\
Alloy 2 & 23.19 & 1.00 & 0.96 & 2.70 & 0.19 & bal. \\
Alloy 3 & 20.76 & 1.10 & 0.01 & 4.00 & 0.21 & bal. \\
\hline
\end{tabular}

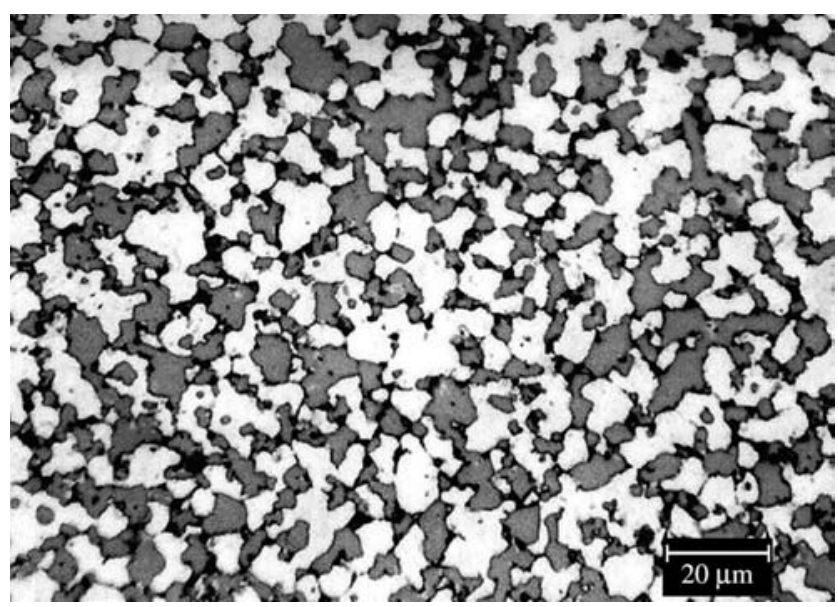

Alloy 1

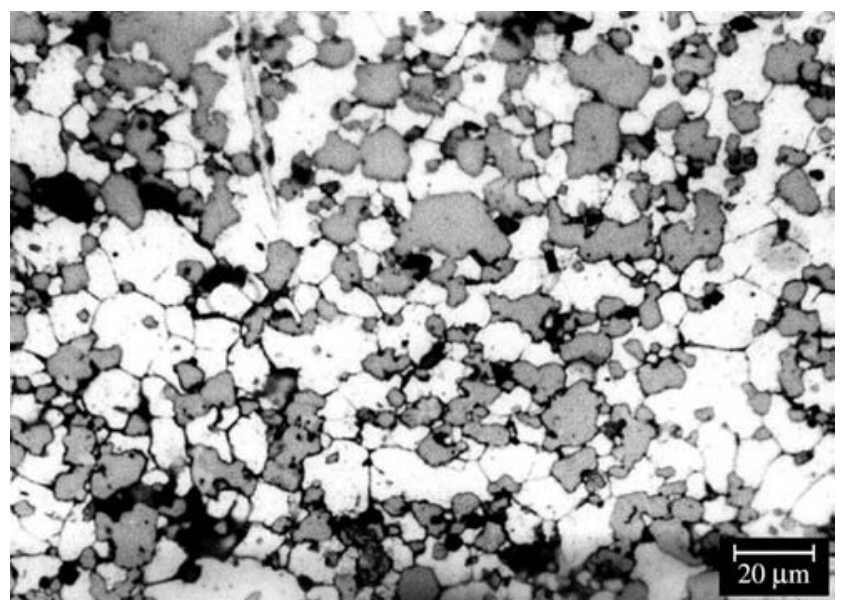

Alloy 2

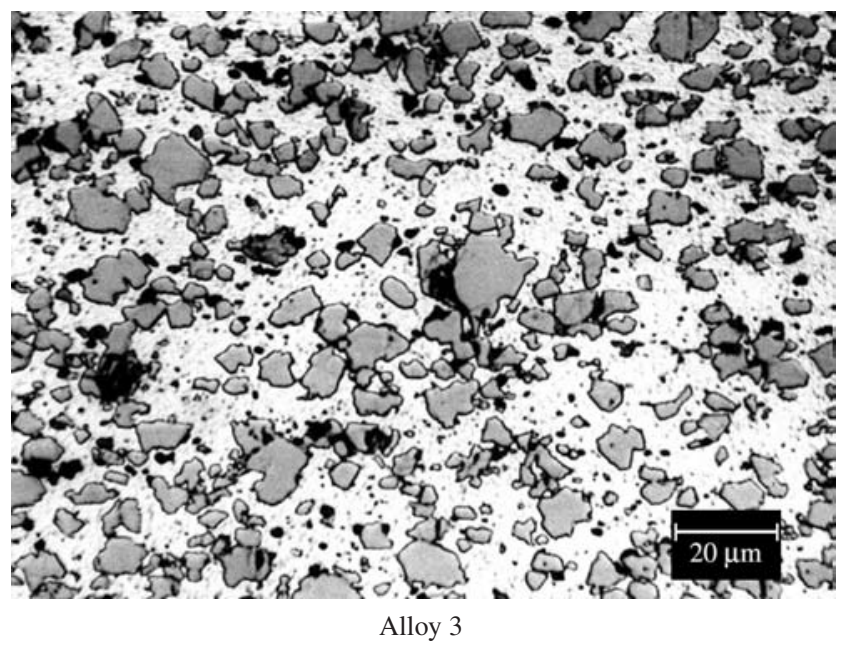

Figure 2. Optical micrographs of the spray formed alloys 1, 2 and 3, showing the homogeneity of the silicon particles distribution (light grey phase) in the aluminium matrix (white phase). 
structure evenly distributed and macrosegregation free.

Figure 3 shows SEM secondary electron micrographs of the alloys 1, 2 and 3. It was observed three different phases: dark grey phase, corresponding to the continuous aluminium matrix. The medium grey phase corresponds to the primary silicon particles (discontinuous phase). The light grey phase is composed by intermetallics, mainly copper rich. These phases were identified by energy dispersive spectroscopy - EDS. Figure 3 clearly show that the size of the primary silicon particles of alloy 1 , are finer than the other alloys.

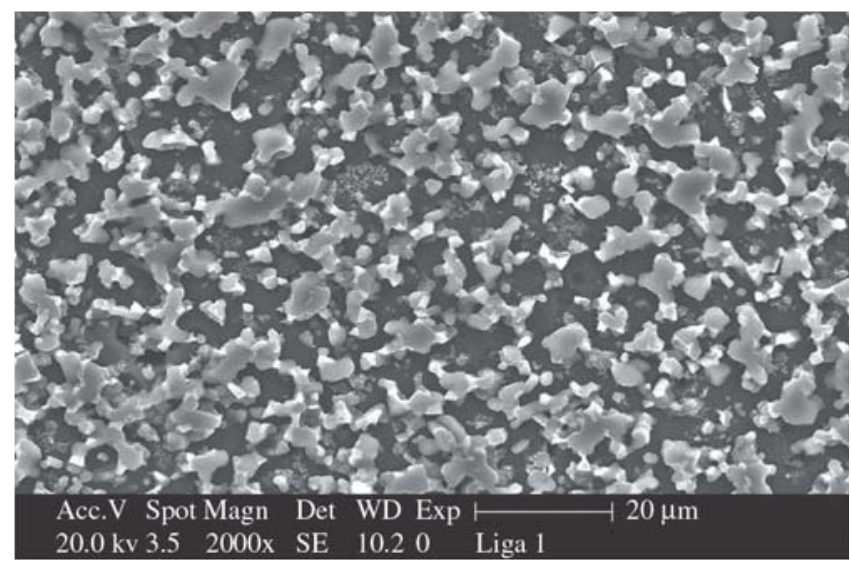

Alloy 1

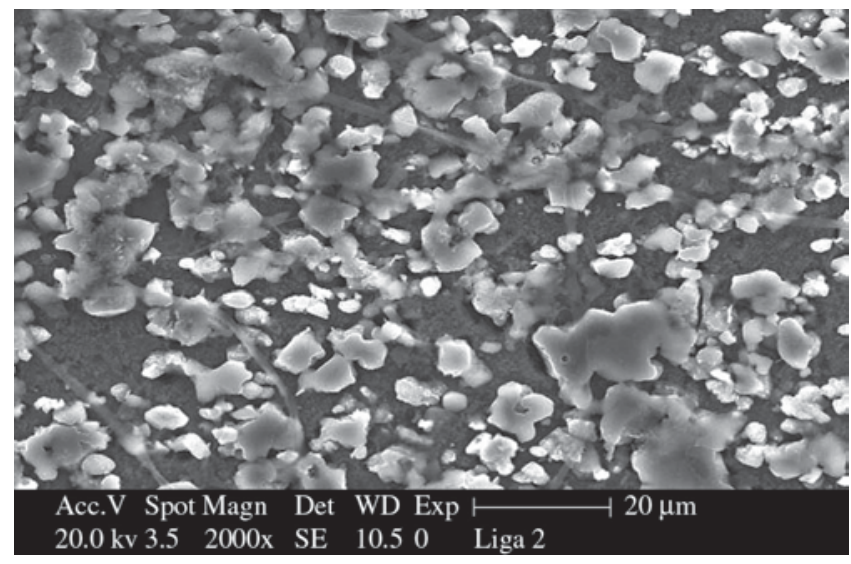

Alloy 2

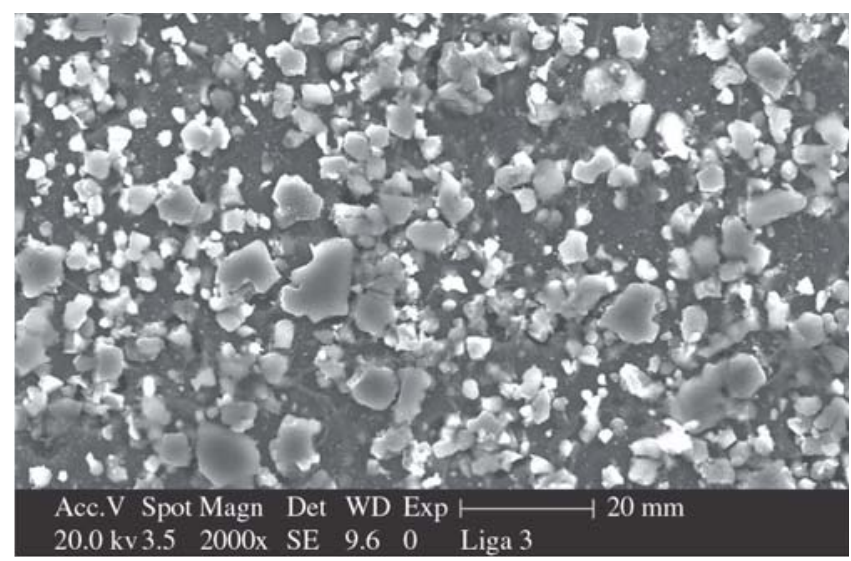

Alloy 3

Figure 3. SEM secondary electron micrographs, presenting three different areas: aluminium matrix (continuous dark grey phase), silicon (discontinuous medium grey phase) and copper rich intermetallics (light grey phase).
It is known that both the aluminium and silicon have FCC structures, furthermore during the spray forming process the silicon dissolves very little in the aluminium matrix due to the high cooling rate inherent of the process. The primary silicon are homogeneously distributed in the matrix, with particles size much smaller than the obtained by conventional processes. In these conditions, the material acts as if it was a heterogeneous mixture, where two FCC structures coexist, having no loss of the characteristics of the aluminium or of the silicon.

Figure 4 presents X-ray diffraction patterns, obtained in a Laue camera, of alloy 1 , hot rolled ( $72 \%$ of reduction) and cold rolled (70\% of reduction). Figure 5 presents the poles figures for alloy 1 hot rolled (a) and cold rolled (b), where the contour lines appear concentric and the largest intensity in "times random" units is 1.57. This alloy under the rolling conditions did not show any preferential orientation direction, which is not common in aluminium alloys. This can be justified by the presence of a large amount of very fine silicon particles (approximately 26\% in weight) and intermetallics that does not undergo plastic deformation. These phases would prevent the texture formation in alloy 1 . The literature on texture of aluminium tubes hot extruded and cold swaged, discussed the texture recrystallization under precipitation influence ${ }^{12}$. As mentioned the presence of precipitates may hinder and even block grain boundary movement ${ }^{12}$. Similarly, the presence of very fine silicon and intermetallics particles would prevent crystalline lattices rotation during mechanical work such as rolling, and consequently the texture development.

Figure 6 presents X-ray diffraction pattern, obtained in a Laue camera for alloy 2 , where the texture is also not observed. The result extracted from the pole figure (Figure 7) confirms the absence of texture.

Figure 8a shows the Laue photograph for alloy 3 regarding the radial direction of the cylinder liner. This Laue photograph is similar to the ones obtained for alloys 1 and 2, where texture is not observed. However, Figure $8 \mathrm{~b}$ shows a Laue photograph taken from the axial direction of the cylinder liner, alloy 3 , where it can be observed variations in the intensity of the Debye rings, which is characteristic of texture. It should be mentioned that the Laue photograph of Figure $8 b$ is not complete, see bottom left corner. This was due to the used specimen that was too small for the available X-ray collimator. The result extracted from the pole figure in the axial direction (Figure 9) confirm the presence of a low intensity texture and the poles are typical of aluminium deformation (times random of 2.13).

The texture observation just in a direction is explained by Cullity, B. D. ${ }^{12}$ that analyses the fibre texture in a material formed by

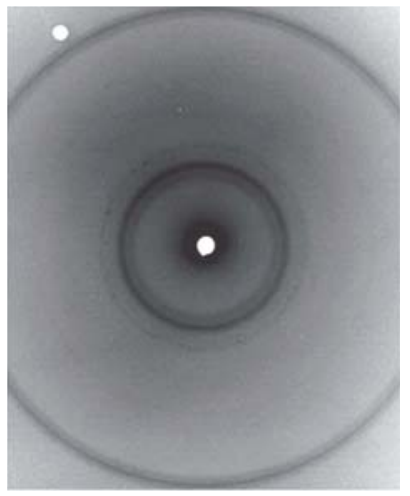

(a)

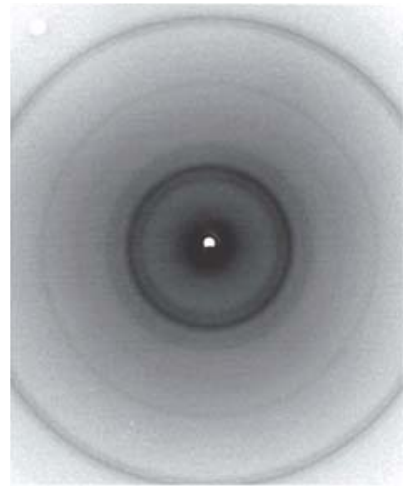

(b)
Figure 4. Laue photographs of specimens taken from alloy 1, perpendicular to the rolling direction: a) Hot rolled at $450{ }^{\circ} \mathrm{C}-72 \%$ total reduction in thickness; b) Cold rolled $-70 \%$ total reduction in thickness. The diffraction lines have a continuous and uniform intensity appearance, which indicate a random crystal orientation. 


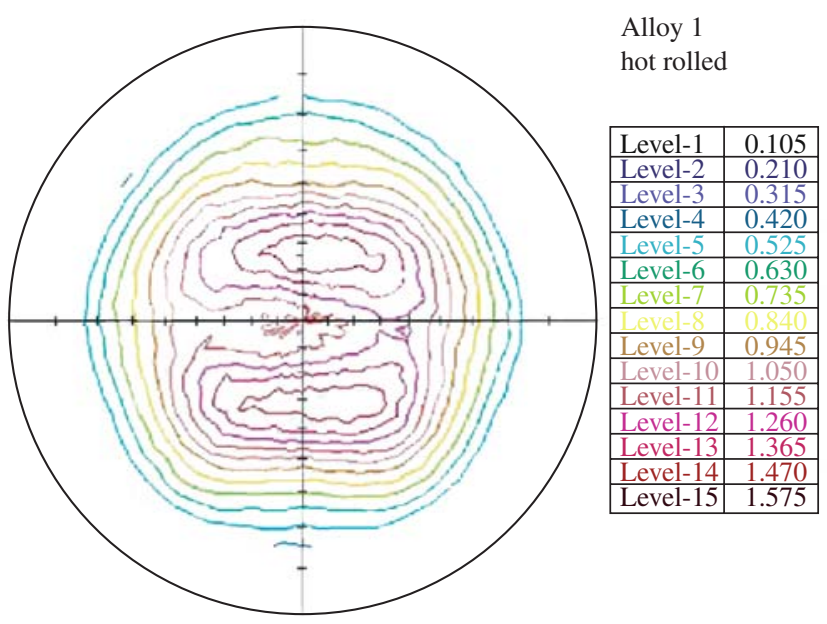

(a)

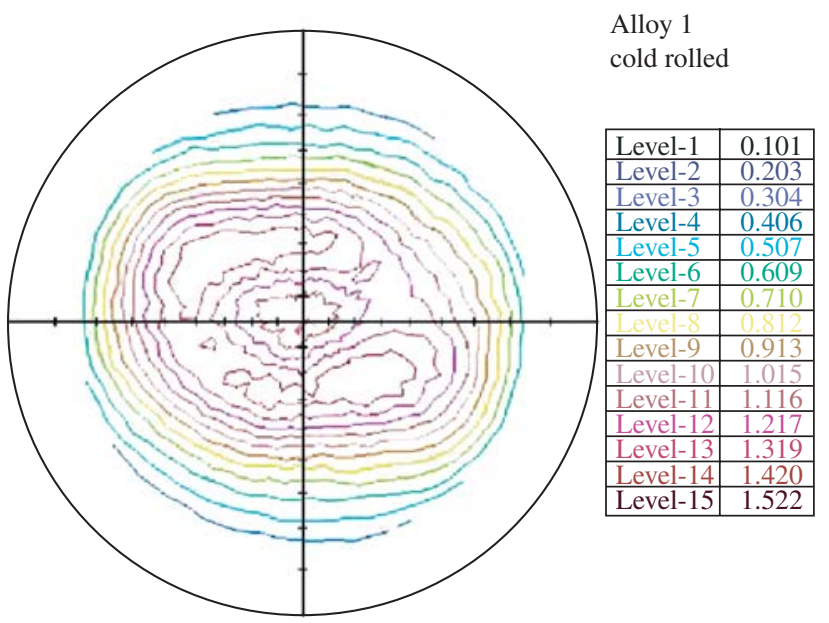

(b)

Figure 5. Pole figures obtained from alloy 1. a) After hot rolling up to $72 \%$ total reduction in height. b) After cold rolling up to $70 \%$ total reduction in height. These pole figures indicate that under the present mechanical working condition, a very low intensity aluminium deformation texture is observed.

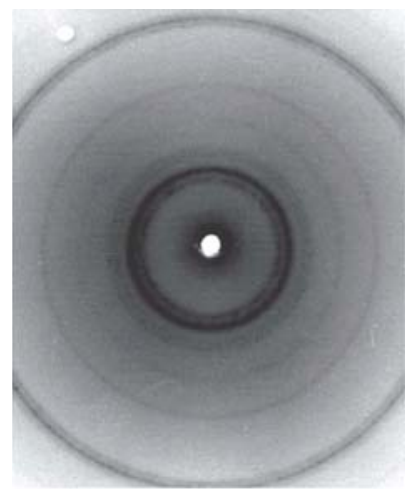

Figure 6. Laue photograph of the specimen taken from alloy 2, radial direction. The diffraction lines have a continuous and uniform intensity appearance, which indicate a random crystal orientation.

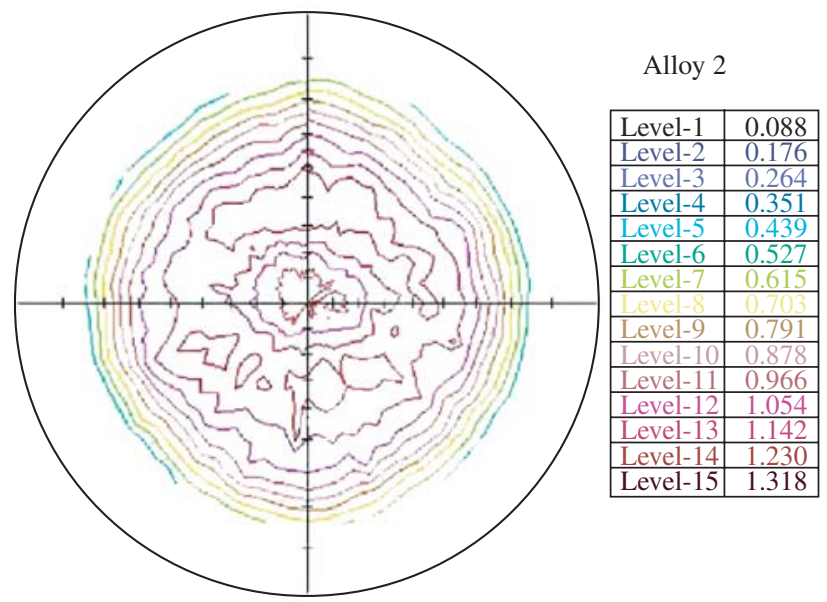

Figure 7. Pole figure obtained from alloy 2, whose specimen was taken from a cylinder liner. This pole figure shows that the specimen has no texture.

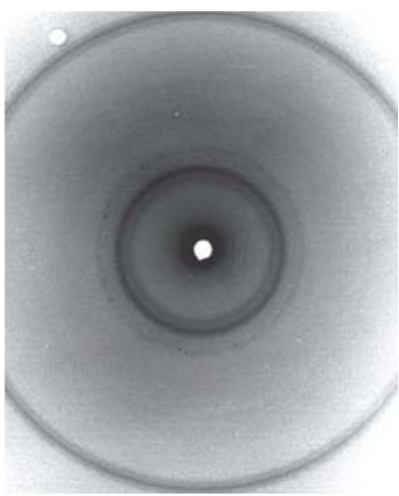

(a)

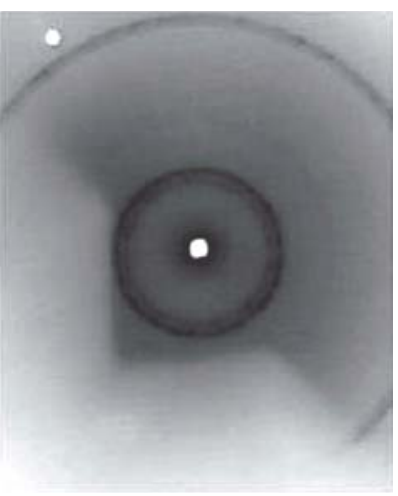

(b)
Figure 8. Laue photographs of the specimens taken from alloy 3. a) Radial direction. b) Axial direction. In the radial direction, the Debye rings are continuous and of uniform intensity and these are due to the incident X-ray beam to be parallel to the fibre axis. In the axial direction, the non-uniform blackening of the Debye rings is due to preferred orientation in the specimen.

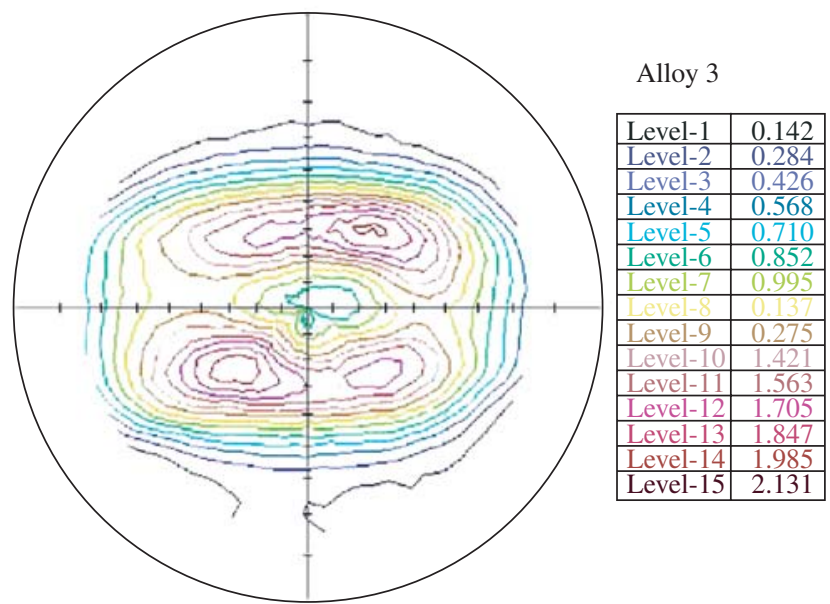

Figure 9. Pole figure obtained from alloy 3, whose specimen was taken from a cylinder liner. This pole figure shows that the specimen has a typical low intensity aluminium deformation texture. 
forces that have rotational symmetry about an axis, for example in wire and rod formed by drawing, swaging, or extrusion. A Debye ring of uniform intensity can be formed if the incident X-ray beam is normal to the sheet specimen and therefore parallel to the fibre axis. Therefore, a uniform Debye ring is not always evidence of randomly oriented grains. BUNGE, H. J. ${ }^{13}$ reported studied textures of swaged aluminium tubes, making a wall cut in the axial direction, opening it and treating it as a sheet shaped sample, but with the aligned fibres texture parallel to the axis of the cylinder.

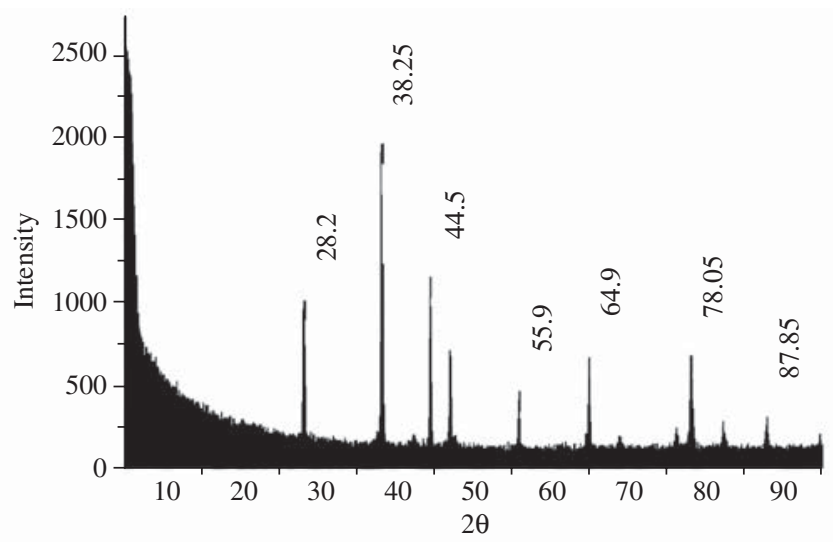

Alloy 1

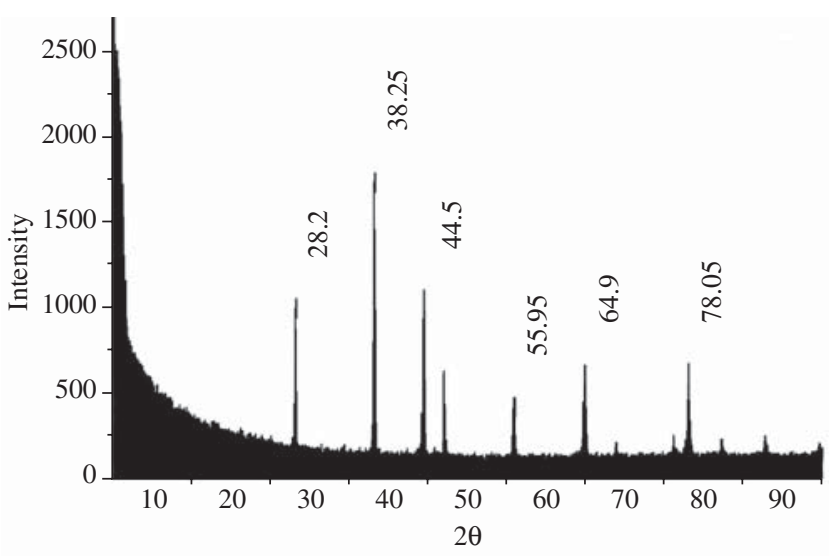

Alloy 2

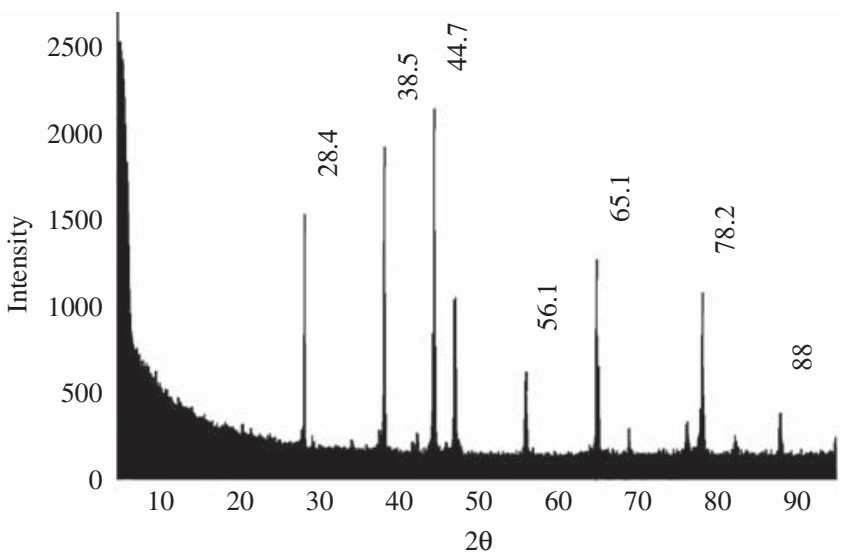

Alloy 3

Figure 10. Diffractometer traces of the spray formed hypereutectic aluminium-silicon alloys.
In a previous work, presented in SDMA $2003^{11}$ it was just analysed the radial directions of the cylinders liners, alloys 2 and 3. In this occasion, the texture hindrance by the spray forming process was verified. The present work comes to complement the previous discussion, besides comparing the existent market alloys with an experimental alloy.

Figure 5 presents the pole figures of alloy 1, hot rolled (a) and cold rolled (b), where the contour lines are concentric, also showing the lack of texture. The pole figures of the alloys 2 and 3 are shown in the Figures 7 and 9, respectively. The alloy 2 does not present texture as well as the alloy 1 . The alloy 3 presents a low intensity deformation texture. The amount of silicon and other intermetallics forming elements in the alloy 3 , is the smallest in relation to the other two alloys. This is a circumstantial evidence that it might be an upper limit for the addition of silicon and other alloying elements into an aluminium, which above it, there is a very little induced deformation texture.

Figure 10 present the X-ray diffraction patterns obtained for the three alloys. The analysis of the spectra shows that both phases (Al and $\mathrm{Si}$ ) are present, and there are no intermediate AlSi phases.

\section{Conclusions}

Regarding alloy 1, which is an experimental Al-Si spray formed alloy, under the used conditions for plastic forming, the hot rolling and cold rolling processes have induced a very low intensity aluminium deformation texture in the alloy.

The specimens taken from a cylinder liner, alloy 2 , under the unknown used forming condition (the transformation of a spray formed Al-Si billet into a tube) have no induced texture.

It is noticed that alloy 3 and respective mechanical work has induced a low intensity deformation texture. Therefore, spray formed microstructure, which is very fine, hinders the texture formation during mechanical work.

\section{Acknowledgments}

The authors thank the Institute of Physics of University of São Paulo for the use of a X-ray diffractometer; the Brazilian Government for awarding a scholarship to $\mathrm{H}$. de O. Santos and FAPESP grant n. 98/07529-5.

\section{References}

1. Crivellone G, Fuganti A, Mus C, Salinas D. Permanent mold gravity casting cylinder block with hypereutectic aluminium liners. SAE Special Publication SP 1610. 2001;p. 77-83.

2. Stocker $P$, Rückert F, Hummert $K$. The new aluminium-silicon cylinder barrel technology for die-cast aluminium crankcases. MTZ Motortechnische Zeitschrift. 1997; 58(9):16-19.

3. Ozbek S, Singer ARE. Some special metal matrix composites (MMCs) produced by spray co-deposition. The Institute of Metals. 1987; 9(1-3).

4. Lavernia EJ, Grant NJ. Spray deposition of metals: a review. Materials Science Engineering. 1988; 98:381-394.

5. Jacobson DM. Spray-formed silicon-aluminium. Advanced Materials \& Process. 2000; 157(3):36-39.

6. Leatham AG, Ogilvy A, Chesney P, Wood JV. Osprey process - production flexibility in materials manufacture. Metals and Materials. 1989; 5:140-143.

7. Leatham AG, Elias L, Yaman M, Itami T, Kawashima Y, Brooks PJS, Hummert K, Tyler DE, Cheskis P, Dalal RP, Prichard PD. Spray forming - commercialisation and applications. Proc. of P/M World Congress. 1992; 23-24:66-76

8. Leatham AG, Ogilvy A, Elias L. The Osprey process current status and future possibilities. P/M in Aerospace, Defense and Demanding Applications Conf. 1993; 7(10):165-175. 
9 Rossi JL, Ambrozio Filho F, Vatavuk J, Falleiros DB. IPEN/CPP Report. São Paulo, Brazil. 1997; p. 1-15. (In Portuguese).

10. Cullity BD. Elements of X-ray diffraction. Addison-Wesley. 1978; 2 ed. p. 295-322.

11. Santos HO, Lima NB, Costa I, Rossi JL, Santos JC, Colosio MA. Crystallographic orientation study of spray formed hypereutectic Al-Si alloys used in the automotive industry. SDMA 2003 and ICSF V. 2003; 1:97-101.

12. Lima NB, Imakuma AK, Padilha AF. Texture of aluminum tubes containing precipitates. $41^{\circ}$ Congress ABM. São Paulo, Brazil. 1986; 2:283-291. (In Portuguese).

13. Bunge HJ. Texture Analysis in Materials Science-Mathematical Methods. Butterworth. 1982; 1 ed. p. 245-247. 